\title{
Peningkatan Kemampuan Pengelolaan Keuangan Rumah Tangga pada Ibu-Ibu RPTRA Sungai Bambu Jakarta Utara
}

\author{
Mary Ismowati a,1,*, Muhammad As'ad ${ }^{\text {a,2 }}$, Rame Soekarsono ${ }^{\text {a,3 }}$, Nidaul Izzah ${ }^{\text {b,4 }}$, Didit Mulyadi a,5 \\ Ma'mun a,6, Moh. Mujakir a,7 \\ a, Magister Administrasi Publik Pasca Sarjana Institut Ilmu Sosial dan Manajemen Stiami \\ ${ }^{\mathrm{b}}$ Administrasi Bisnis, Institut Ilmu Sosial dan Manajemen Stiami \\ 1 maryismo@yahoo.com* \\ * corresponding author
}

\section{ARTICLE INFO}

\section{Article history}

Received

Revised

Accepted

Keywords

Financial Management, RPTRA Sungai Bambu

Village,

Housewives

\begin{abstract}
$A B S T R A C T$
Managing personal finances is a reality that must be faced by everyone in everyday life, where a person must be able to manage his personal finances and his household well in order to balance between income and expenses, to meet all the necessities of life and not get caught up in financial difficulties. Managing personal and household finances is not an easy thing to do because there are only difficulties faced by everyone, where one of the difficulties faced is the phenomenon of consumer behavior that is growing rapidly in the community. Likewise, the problem faced by housewives in Sungai Bambu Kelurahan, Tanjung Priok Sub-district, North Jakarta, so that a household financial management training activity was held as a solution to the problem.

Some factors that support the implementation of this activity are the great interest and enthusiasm of the mothers as participants of the activity so that the activity takes place smoothly and in an orderly manner. While the inhibiting factor is the limited time of training. This activity can increase knowledge and understanding of RPTRA Sungai Bambu Village, Tanjung Priok Subdistrict, North Jakarta, increase knowledge about tips to deal with obstacles in managing household finances RPTRA, Sungai Bambu Village, Tanjung Bambu District, North Jakarta District, and increase knowledge and understanding of the RPTRA of Sungai Bambu Village, Tanjung Priok District, North Jakarta about the need for halal financial resources in financial management

Considering the magnitude of the benefits of the activity, then it is necessary to hold a Financial Management training for every woman or RPTRA in DKI Jakarta as well as the continuity and monitoring of the program.
\end{abstract}

\section{A. PENDAHULUAN}

\section{Analisis Situasi}

Dalam kehidupan sehari-hari sering ditemukan masalah yang berhubungan dengan keuangan. Mengatur keuangan merupakan persoalan klasik di kehidupan. Ada beberapa orang yang sering kali mengalami yang namanya krisis keuangan, misalnya selalu merasa kurang dengan penghasilan atau uang bulanan. Krisis keuangan terjadi pada umumnya bukan karena kurangnya penghasilan tapi seringkali karena pengaturan keuangan yang tidak tepat.

Horne dan Wachowicz Jr. (2012:2) dalam bukunya yang berjudul Fundamentals of Financial Management yang telah di alih bahasa menjadi Prinsip-prinsip Manajemen Keuangan mengemukakan bahwa "Manajemen keuangan berkaitan dengan perolehan aset, pendanaan, dan manajemen aset dengan didasari beberapa tujuan umum". Sedangkan menurut Irham Fahmi (2013:2), mengemukakan bahwa: "Manajemen Keuangan merupakan penggabungan dari ilmu dan seni yang membahas, mengkaji dan menganalisis tentang bagaimana seorang manajer keuangan dengan mempergunakan seluruh sumberdaya perusahaan untuk mencari dana, mengelola dana dan membagi dana dengan tujuan memberikan profit atau kemakmuran bagi para pemegang saham dan suistainability (keberlanjutan) usaha bagi perusahaan."

Mengelola keuangan pribadi merupakan kenyataan yang harus dihadapi oleh setiap orang dalam kehidupan sehari-hari, dimana seseorang harus mampu mengelola keuangan pribadinya maupun rumah tangganya dengan baik agar dapat menyeimbangkan antara pendapatan dan pengeluaran, dapat memenuhi 
semua kebutuhan hidup serta tidak terjebak dalam kesulitan keuangan. Menerapkan cara pengelolaan keuangan yang benar, maka seseorang diharapkan bisa mendapatkan manfaat yang maksimal dari uang yang dimilikinya pada saat ini sehingga pada akhirnya dapat bermanfaat bagi peningkatan kesejahteraan hidupnya.

Namun mengelola keuangan pribadi dan rumah tangga bukanlah hal yang mudah untuk dilakukan sebab ada saja kesulitan yang dihadapi oleh setiap orang ,dimana salah satu kesulitan yang dihadapi adalah fenomena perilaku konsumtif yang berkembang pesat di kalangan masyarakat. Demikian juga masalah yang dihadapi Ibu-ibu rumah tangga di daerah Kelurahan Sungai Bambu Kecamatan Tanjung Priok Jakarta Utara, karena kemampuan pengetahuan yang terbatas, mengalami berbagai kesultan dalam mengelola rumah tangga termasuk pengelolaan keuangan. Pemerintah membantu mengatasi keterbatasan pengetahuan para Ibu-ibu ini dengan mengadakan berbagai kegiatan dan pelatihan sederhana.

Pemerintah Provinsi DKI Jakarta mempunyai Program penyediaan sarana ruang interaksi social masyarakatnya termasuk bagi para ibu rumah tangga disebut RPTRA ( Ruang Publik terbuka Bagi Anak) . Program kerja membangun fasilitas public RPTRA ini dikarenakan adanya keterbatasan lahan lingkungan rumah masyaraat di Jakarta.

Permasalahan keterbatasan lahan lingkungan rumah yang ada di kota-kota besar Indonesia khsususnya Jakarta sebagai ibukota Indonesia karena kepadatan penduduk yang tinggi sementara luas lahan bersifat tetap dan terbatas. Pada tahun 2015, DI DKI Jakarta tercatat sebanyak 55,61 \% rumah tangga memiliki luas lantai rumah dibawah $50 \mathrm{~m} 2$ dan sebanyak $20,92 \%$ memiliki luas lahan diatas $100 \mathrm{~m} 2$. Hal ini dapat mengindikasikan semakin sempitnya lahan di Jakarta yang menjadi hunian.Berkembangnya industrI, bisnis di Jakarta membuat Jakarta tetap menjadi tujuan urbanisasi akibatnya kepadatan penduduk Jakarta semakin tinggi. Keterbatasan lahan ini menyebabkan munculnya pemukiman penduduk yang sangat padat dan cenderung menjadi pemukiman kumuh. Bermunculan pemukiman kumuh di lokasi yang tidak layak seperti di bantaran sungai, di kolong jembatan, di sisi rel kereta dan lain-lain.

Dengan kondisi tersebut maka pemukiman penduduk ini tidak mempunyai fasilitas umum yang memadai. Masyarakat tidak mempunyai tempat untuk berinteraksi dengan baik, dimana masyarakat dapat melakukan aktivitas bersama. Permasalahan ini menjadi tanggung jawab pemerintah DKI untuk mengatasinya. Karena tugas utama pemerintah adalah menyelesaikan semua permasalahan publik. Tuntutan masyarakat untuk memperoleh pelayanan yang lebih baik harus disikapi sebagai upaya untuk menciptakan kepuasan dalam pemberian pelayanan kepada masyarakat

Ada tiga fungsi utama yang harus dijalankan oleh pemerintah, yaitu Fungsi Pelayanan Masyarakat, Fungsi Pembangunan, dan Fungsi Perlindungan Thoha (1995:101). Fungsi Pelayanan Masyarakat merupakan salah satu fungsi pemerintah sebagai alat pemuas kebutuhan masyarakat melalui penyediaan barang dan jasa.

Dalam administrasi publik apa yang dimaksud dengan kepentingan publik dan bagaimana kepentingan publik diwujudkan tidak hanya tergantung pada lembaga negara. Kepentingan publik harus dirumuskan dan diimplementasikan oleh semua aktor baik negara, bisnis, maupun masyarakat sipil. Pandangan semacam ini yang menjadikan paradigma NPS disebut juga sebagai Paradigma Governance. Teori Governance berpandangan bahwa negara atau pemerintah di era global tidak lagi diyakini sebagai satu-satunya institusi atau aktor yang mampu secara efisien, ekonomis dan adil menyediakan berbagai bentuk pelayanan publik sehingga paradigma governance memandang penting kemitraan (partnership) dan jaringan (networking) antar banyak stakeholders dalam penyelenggaraan urusan publik.

Pemerintah daerah dalam upaya memberikan pelayanan yang lebih baik kepada masyarakat secara adil, merata, cepat dan tepat, telah menjalin kerjasama dengan pihak swasta. Salah satu bentuk kemitraaan swasta dalam bidang pelayanan public. Upaya memperbanyak ruang interaksi bagi warga Ibukota terus dilakukan Pemerintah Provinsi (Pemprov) DKI Jakarta dengan membangun Ruang Publik Terpadu Ramah Anak (RPTRA) dibangun dengan tujuan memberikan ruang interaksi bagi 90 persen dari total sekitar 10,2 juta warga Ibukota. Aktivitas sosial dapat diartikan sebagai kegiatan yang membutuhkan kehadiran orang lain (Zhang dan Lawson, 2009). Kegiatan ini dapat berupa perbincangan santai di pinggir jalan, bertatap muka maupun kegiatan anak-anak bermain di taman kota. Penanganan ruang publik yang kreatif dapat mendukung terbentuknya aktivitas sosial antara orang-orang yang tidak saling mengenal sebelumnya. Adanya pementasan kesenian di taman kota dapat menjadi contoh. Kegiatan-kegiatan kreatif yang diselenggarakan di ruang-ruang terbuka (baik yang bertujuan komersial maupun non-komersial) dapat 
mendorong warga untuk saling berbincang atau sekedar saling mengomentari kegiatan kreatif tersebut, demikian juga dengan pemasangan karya seni instalasi di ruang publik.

Dalam kajiannya, Zhang dan Lawson (2009) mempergunakan tiga klasifikasi aktivitas pada ruang publik, antara lain : - Aktivitas proses. Aktivitas ini dilakukan sebagai peralihan dari dua atau lebih aktivitas utama. Bentuk dari aktivitas ini biasanya pergerakan dari suatu tempat (misalnya rumah) ke kios (aktivitas konsumsi). - Kontak fisik. Aktivitas ini dilakukan dalam bentuk interaksi antara dua orang atau lebih yang secara langsung melakukan komunikasi atau aktivitas sosial lainnya. - Aktivitas transisi. Aktivitas ini dilakukan tanpa tujuan yang spesifik yang biasanya dilakukan seorang diri, seperti duduk mengamati pemandangan dan lain sebagainya

RPTRA yang telah terbangun dan beroperasi saat ini dibiayai dari program Corporate Social Responsibility (CSR) pihak swasta dan Anggaran Pendapatan dan Belanja Daerah (APBD) DKI. RPTRA ini dibangun dengan berbagai kegiatan yang ditujukan bagi ibu-ibu rumah tangga : (Konseling, pelatihan singkat, demo masak, dan lain-lain). Juga bagi Kegiatan anak-anak: Taman bermain, Les belajar bersama, perpustakaan. Dan juga untuk kegiatan bagi bapak-bapak seperti Pertemuan, dan lain-lain.

Masyarakat DKI Jakarta diharapkan berpartisipasi dalam mensukseskan program RPTRA dengan berbagai kegiatannya, termasuk juga Dosen khususnya Dosen Pasca sarjana Institut Stiami.. Sebagai Dosen yang mempunyai kewajiban Tridharma, yaitu Pengajaran, Penelitian dan Pengabdian kepada masyarakat tentu diharapkan sumbangsih pemikiran dan tenaga untuk mengatasi permasalahan di masyarakat (Bakti et al., 2017). Peranan Dosen Pasca sarjana Institut Stiami dalam PkM ( Pengabdian kepada masyarakat) pada program RPTRA di Kelurahan Sungai Bambu Kecamatan Tanjung Priok Jakarta, untuk menyelesaikan masalah keterbatasan pengetahuan ibu rumah tangga dalam pengelolaan rumah tangga, inilah yang menjadi tujuan dalam kegiatan PKM ini.

\section{Perumusan masalah}

1. Bagaimanakah pengelolaan keuangan rumah tangga ibu-ibu RPTRA di Kelurahan Sungai Bambu Kecamatan Tanjung Priok Jakarta ?

2. Kendala apa yang dihadapi dalam pengelolaan keuangan rumah tangga ibu-ibu RPTRA di Kelurahan Sungai Bambu Kecamatan Tanjung Priok Jakarta ?

3. Seberapa penting sumber-sumber keuangan yang halal dalam pengelolaan keuangan rumah tangga ibuibu RPTRA di Kelurahan Sungai Bambu Kecamatan Tanjung Priok Jakarta

\section{Tujuan Kegiatan}

1. Menjelaskan pengelolaan keuangan rumah tangga pada ibu-ibu RPTRA kelurahan Sungai Bambu Kecamatan Tanjung Priok.

2. Menjelaskan kendala yang dihadapi dan kiat-kiatnya dalam pengelolaan keuangan rumah tangga pada ibu-ibu RPTRA kelurahan Sungai Bambu Kecamatan Tanjung Priok.

3. Menjelaskan pentingnya sumber-sumber keuangan yang halal dalam pengelolaan keuangan rumah tangga pada ibu-ibu RPTRA kelurahan Sungai Bambu Kecamatan Tanjung Priok.

\section{Manfaat Kegiatan}

Setelah memahami dan menguasai konsep Rumah tangga dan Pengelolaan Keuangan ibu-ibu RPTRA Kelurahan Sungai Bambu Kecamatan Tanjung Priok.mampu memahami cara-cara pengelolaan keuangan rumah tangga dan juga manfaat sumber-sumber keuangan yang halal sesuai dengan ajaran Al-Qur'an dan Hadist.agar memperoleh keberkahan dalam pengelolaannya.

\section{Kerangka Pemecahan Masalah}

Alternatif Pemecahan Masalah, yaitu menambah pengetahuan para ibu rumah tangga di kelurahan Sungai Bambu Kecamatan Tanjung Priok tentang pengelolaan laporan keuangan maka dilakukan kegiatan Pengabdian kepada masyarakat dosen Pascasarjana Institut STIAMI yang kompetensinya sesuai dengan melibatkan mahasiswa.

Adapun dosen Pascasarjana Institut STIAMI yang terlibat sebagai berikut :

1. Dr. Muhammad As'ad,SE.,MM

2. Dr.Mary Ismowati

3. Dr. Rame Soekarsono 
4. Nidaul Izzah,M.Ak

5. Didit Mulyadi

6. Ma'mun

7. Moh. Mujakir

Ada 2 tema dalam kegiatan PKM ini, yaitu :

1. Pelatihan dan praktik sederhana membuat pengelolaan keuangan bagi ibu-ibu RPTRA kelurahan Sungai Bambu Kecamatan Tanjung Priok.

2. Praktek membuat nugget krispi ikan tuna untuk meningkatkan gizi keluarga dan alternative peluang usaha.

\section{B. PELAKSANAAN DAN METODE}

\section{Realisasi Pemecahan Masalah}

Persiapan kegiatan pengabdian kepada masyarakat. Sebelum kegiatan dilaksanakan maka dilakukan persiapan-persiapan sebagai berikut:

1. Melakukan studi pustaka tentang Rumah Tangga dan Pengelolaan Keuangan

2. Melakukan persiapan materi pelatihan tentang Manajemen Pengelolaan Keuangan Rumah Tangga.

3. Menentukan waktu dan tempat pelaksanaan kegiatan pengabdian bersama-sama tim pelaksana

\section{Pelaksanaan kegiatan pengabdian}

Pelaksanaan kegiatan pengabdian berlangsung pada hari 6-9 Maret 2018 jam 09.00-12.00 yang dihadiri oleh 100 peserta (Ibu-ibu RPTRA Kelurahan Sungai Bambu Kecamatan Tanjung Priok Jakarta Utara)

\section{Relevansi Bagi Ibu-Ibu}

Kegiatan pengabdian ini memiliki relevansi dengan perubahan sikap individu dalam tata cara mengelola keuangan sesuai dengan Alqur'an dan Al-Hadist dan juga ilmu dasar keuangan bagi para Ibu-ibu RPTRA Kelurahan Sungai Bambu Kecamatan Tanjung Priok Jakarta Utara.

\section{HASIL DAN PEMBAHASAN}

\section{Hasil Kegiatan}

RPTRA Kelurahan Sungai Bambu Kecamatan Tanjung Priok Jakarta Utara dikelola oleh kelurahan dengan melibatkan masyarakat untuk memfasilitasi ruang pertemuan publik sebagai sarana interaksi sosial masyarakat. Adapun susunan kepengurusan pengelola RPTRA Kelurahan Sungai Bambu Kecamatan Tanjung Priok Jakarta Utara terdiri atas :

1. Ketua : istri Lurah Kelurahan Sungai Bambu Kecamatan Tanjung Priok Jakarta Utara

2. Manajer Harian : Profesional yang diangkat melalui seleksi

3. Petugas : Ibu rumah tangga di lingkungan kelurahan yang terpilih

RPTRA Kelurahan Sungai Bambu Kecamatan Tanjung Priok Jakarta Utara mempunyai berbagai program :

1. Untuk ibu-ibu rumah tangga : (Konseling, pelatihan singkat, demo maska, dan lain-lain)

2. Kegiatan anak-anak : Taman bermain, Les belajar bersama, perpustakaan

3. Kegiatan bagi bapak-bapak : Pertemuan, dan lain-lain 
Gambar-gambar berikut menunjukkan kegiatan pelatihan yang dilakukan pada kegiatan ini
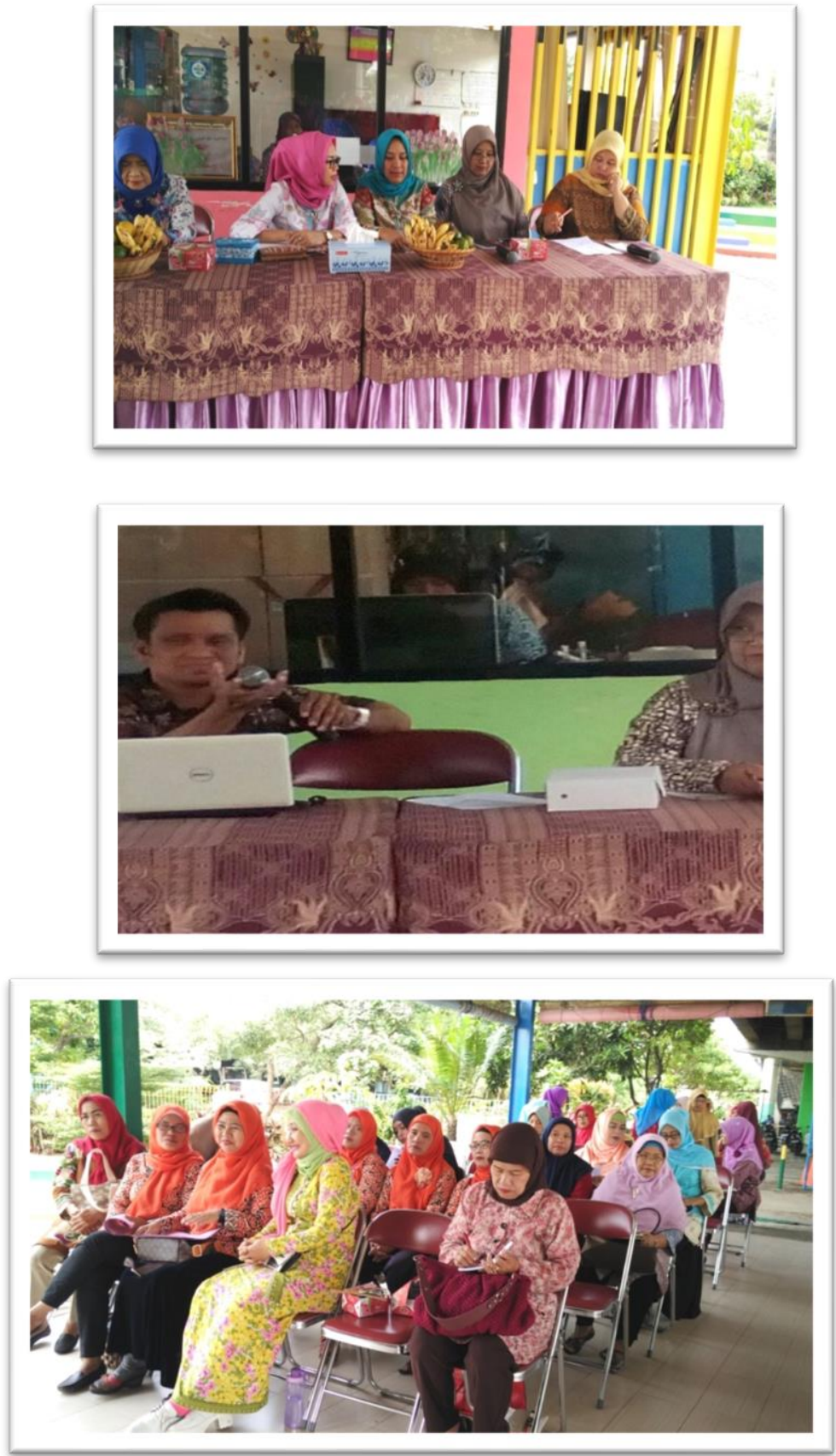

Gambar 1. Foto Kegiatan Pelatihan Pengelolaan Keuangan Rumah Tanggadi RPTRA Kelurahan Sungai Bambu

Berdasarkan wawancara dan tanya jawab kegiatan pengabdian ini memberikan hasil sebagai berikut:

a. Meningkatkan pengetahuan tentang Pengelolaan Keuangan rumah tangga bagi ibu-ibu di RPTRA Kelurahan Sungai Bambu Kecamatan Tanjung Priok Jakarta Utara

b. Memberikan pemahaman tentang pentingnya Pengelolaan Keuangan rumah tangga bagi ibu-ibu di RPTRA Kelurahan Sungai Bambu Kecamatan Tanjung Priok Jakarta Utara

c. Menanamkan kesadaran perlunya sumber keuangan yang halal dalam pengelolaan keuangan rumah tangga bagi ibu-ibu di RPTRA Kelurahan Sungai Bambu Kecamatan Tanjung Priok Jakarta Utara

\section{PEMBAHASAN}

Beberapa faktor yang mendukung terlaksananya kegiatan pengabdian dengan melakukan pelatihan adalah besarnya minat dan antusiasme para ibu-ibu sebagai peserta kegiatan sehingga kegiatan berlangsung dengan lancar dan tertib. Sedangkan faktor penghambatnya adalah keterbatasan waktu pelatihan. 


\section{E. PENUTUP}

\section{Simpulan}

Dari kegiatan pengabdian pada masyarakat ini dapat disimpulkan bahwa kegiatan ini meningkatkan pengetahuan dan pemahaman Ibu-ibu RPTRA Kelurahan Sungai Bambu Kecamatan Tanjung Priok Jakarta Utara, menambah pengetahuan tentang kiat-kiat menghadapi kendala dalam pengelolaan keuangan rumah tangga Ibu-ibu RPTRA Kelurahan Sungai Bambu Kecamatan Tanjung Priok Jakarta Utara, serta menambah pengetahuan dan pemahaman Ibu-ibu RPTRA Kelurahan Sungai Bambu Kecamatan Tanjung Priok Jakarta Utara tentang perlunya sumber-sumber keuangan yang halal dalam pengelolaan keuanagan

\section{Saran}

Mengingat besarnya manfaat kegiatan pengabdian berupa pelatihan tema Pengelolan Keuangan rumah tangga di RPTRA Kelurahan Sungai Bambu Kecamatan Tanjung Priok Jakarta Utara maka selanjutnya perlu diadakan pelatihan Pengelolaan Keuangan bagi ibu-ibu di setiap atau RPTRA di DKI Jakarta dan adanya kesinambungan dan monitoring program Dosen Pascasarjana Institut STIAMI Jakarta dalam kegiatan pengabdian kepada masyarakat (PKM) pelatihan, sehingga Ibu-ibu dapat mengaplikasikannya dalam setiap kegiatannya.

\section{F. DAFTAR PUSTAKA}

[1]. Al-Qur'an dan terjemahannya, Departemen Agama Republik Indonesia, Pustaka Agung Harapan,2006

[2]. Bakti, A. F., Vikaliana, R., Regantini, Khumaidi, A., Florentina, Jarkawi, Khasanah, Rumbekwan, M., Rajagukguk, J., Wibowo, E. W., Ri'aeni, I., \& Sayekti, T. (2017). Seminar Nasional Membangun Tingkat Kompetensi Tridarma Perguruan Tinggi untuk Pengembangan Kota Jakarta. https://scholar.google.co.id/citations?user=VWBjbtgAAAAJ\&hl=id\#d=gs_md_cita-

$\mathrm{d} \& \mathrm{u}=\% 2 \mathrm{Fcitations} \% 3 \mathrm{Fview} \_0$ \%3Dview_citation\%26hl\%3Did\%26user\%3DVWBjbtgAAAAJ\%26cst art\%3D20\%26pagesize\%3D80\%26citation_for_view\%3DVWBjbtgAAAAJ\%3AUebtZRa9Y70C\%26tz om $\% 3 \mathrm{D}-420$

[3]. Jr Wachowicz \&Horne, 2012, Fundamental of Financial management.

[4]. Thoha, Miftah. 1995. Birokrasi Indonesia di era Globalisasi, Yogyakarta: Widya Mandala

[5]. Setiawan, 2004, Ensklopedi Nasional Indonesia,PT. Delta pamungkas 